Jerzy Boryczka and Maria Stopa-Boryczka

\title{
THE MULTIPERIODICAL CHANGES OF AIR TEMPERATURE IN WARSAW
}

The aim of the paper is to define the age anomalies of Polish climate and their causes on the basis of over 200-years' series of measurements of air temperature in Warsaw in the years 1779-1979, of Wolf's numbers in the years 1700-1978 and of frequency of atmospheric circulation in the years $1891-1967$.

The periodicity of variables mentioned above was examined, assuming the sinusoidal dependence on time $t$

$$
y=f(t)=a+b \sin \left(\frac{2 \pi}{T} t+c\right)
$$

where $b-$ amplitude, $c-$ phase and $T$ - period (parameter).

The time unit is a tropical year, and the beginning $(t=0)$ are the left-sided limits of observation sections. Changing the parameter $T$ sine curve period (1) - every $\Delta T=1$ or every 0.1 years in sections: temperature $0<T \leqslant 250$, Wolf's numbers $0<T \leqslant 400$, circulation $0<$ $<T \leqslant 100$, the local $T_{r}$ minima of remainder variance were found.

$$
\varepsilon^{2}(T)=\frac{1}{\mathrm{~N}} \sum_{j=:}^{N}\left[y_{\mathrm{j}}-f\left(t_{\mathrm{j}}\right) \mathrm{j}^{2}\right.
$$

in other words, the searched cycles of variables $y$.

In that way cycles $T_{\mathrm{r}}$ which are longer than durations of measurement sequences $y_{1}, \ldots, y_{\mathrm{N}}$ taken in moments $t_{1}, \ldots, t_{\mathrm{N}}$ were calculated.

Every local minimum $\mathrm{T}_{\mathrm{r}}$ of remainder variance $\varepsilon^{2}$ corresponds to the minimum of standard error $\Delta=\sqrt{\frac{N}{N-3}} \varepsilon$ and to maxima: of correlational function $R\left[y_{j}, f\left(t_{j}\right)\right], j=1, \ldots, N$, of determinant coefficent $R^{2}=1-\frac{\varepsilon^{2}}{s^{2}}$ (s- standard deviation of $\mathrm{y}$ ), and of Fisher's characteristic $F_{\text {comp }}=\frac{N-3}{2} \cdot \frac{R^{2}}{1-R^{2}}$ of $n_{1}=2$ and $n_{2}=N-3$ of freedom degrees. 


\section{THE SEASONAL CHANGES IN THE SUN'S ACTIVITY}

In astronomical and climatological literature the short cycles of 11 , 22 years and long ones of 89-110 years of sunspots have been known. It has turned out that Wolf's numbers prove the cyclic changes of other important periods. Cycles of the Sun's activity $T$, their amplitudes $b$ and phases $c$ obtained on the grounds of empirical data, of Wolf's numbers catalogue from the years 1700-1978 (Reznikov, 1982), are compared in Table 1 . Cycles of $\mathrm{T}=11.1,45,56,95,180>400$ years

Table 1

The Sun's Activity Cycles T, Their Amplitudes b and Phases c (1700-1978)

\begin{tabular}{|c|c|c|c|c|c|c|}
\hline $\mathrm{T}_{\mathrm{r}}$ & Years & $a$ & $b$ & $\mathrm{c}$ & Date & $F_{\text {comp }}$ \\
\hline $\mathrm{T}_{1}$ & 5 & 47.33 & 3.682 & -2.824 & 1821 & 0.656 \\
$\mathrm{~T}_{2}$ & 11.1 & 47.44 & 28.08 & -1.525 & 1822 & 51.21 \\
$\mathrm{~T}_{3}$ & 17 & 47.26 & 4.711 & 0.775 & 1813 & 1.069 \\
$\mathrm{~T}_{4}$ & 21.4 & 47.32 & 4.363 & 0.942 & 1820 & 0.918 \\
$\mathrm{~T}_{5}$ & 25 & 47.37 & 3.099 & -2.623 & 1804 & 0.469 \\
$\mathrm{~T}_{6}$ & 29 & 47.49 & 5.408 & 2.435 & 1797 & 1.391 \\
$\mathrm{~T}_{7}$ & 33 & 47.42 & 3.248 & 2.427 & 1811 & 0.510 \\
$\mathrm{~T}_{8}$ & 3.8 & 47.50 & 4.600 & -3.033 & 1823 & 1.031 \\
$\mathrm{~T}_{9}$ & 45 & 47.44 & 9.278 & 2.827 & 1803 & 4.131 \\
$\mathrm{~T}_{10}$ & 56 & 47.29 & 13.87 & -1.910 & 1815 & 9.722 \\
$\mathrm{~T}_{11}$ & 95 & 47.22 & 18.15 & -2.693 & 1812 & 17.94 \\
$\mathrm{~T}_{12}$ & 180 & 46.51 & 9.856 & -1.32 .1 & 1873 & 4.801 \\
$\mathrm{~T}_{13}$ & 400 & 49.05 & 7.423 & -2.872 & 1783 & 2.508 \\
\hline
\end{tabular}

have the biggest amplitudes $b=28.08,9.28,13.87,18.15,9.86,7.42$. They are essential to $99 \%$ of confidence level, because $F_{\text {comp }}$ is bigger than the critical value 4.69 at $n_{1}=2$ and $n_{2}=276$ of freedom degrees. The exception is the 45-years' cycle - essential to $95 \%$ of confidence level. In other cases (also in the case of 21.4-years' cycle) there is no reason to reject zero hypothesis $H(b=0)$ for $10 \%$ of significance level. The strongest are 11.1-years' and 95-years' cycles with coefficents of determination of $27 \%$ and $11.5 \%$.

Despite the amplitude $\mathrm{b}$ and phase $\mathrm{c}$, the dates of minima reckoned cycles of the Sun's astivity; sine curves periods (1); were presented

$$
\text { Date }=1700+\frac{T}{2 \pi}\left(c-\frac{3}{2} \pi\right)+k T, \quad k=0, \pm 1, \ldots
$$


Thus, the minimum of 95-years' cycle - 1812 is the lower limit of the weakest 11-years' cycle of the Sun's activity in the years 1811-1823 - the absolute minimum of Wolf's numbers. The following minima in the 11.1-years' cycle in the years 1811,1822 nearly agree with the dates of the minimal Sun's activity. There are the dates of other multiperiodical minima of the Sun's activity in the 95-years' cycle: $1622,1717,1812,1907,2002$. On the other hand, the minimum of the Sun's activity in multiperiodical cycle of 180 years occurs in the years $1693,1873,2063$. The forecasting minima of the Sun's activity in 45 , $56,95,180$ and over 400-years' cycles occur in the years 1884, 1983, 2002,2063 and 2182 . In the years $1700-1978$ the average value of Wolf's numbers was $\bar{y}=47,33$, and the standard deviation was $\mathrm{s}=$ $=38.18$.

\section{THE PERIODICAL CHANGES OF ATMOSPHERIC CIRCULATION}

Analogicaily counted cycles of an east, west and meridional circulation (according to Vangenheim classification) on the basis of the USRR Hydrological Meteorological Service data, taken from Stachy publications (1970), have been compiled in Table 2. The number of days in the year of east air circulation, shows cycles of $16,27,46$ and 100 years of $20,25,18,26$ days amplitudes - essential to $95 \%$ of confidence level $\left(F_{\text {comp }}>3.11\right.$ ). The cycle of 46 years of an east circulation is probably conditioned by the cycle of the same length (45 years) of the Sun's activity. The extrema of those cycles are synchronous in the years 1891-1967. The minima of an east circulation in 46 years appear in the years: $1898,1944,1990$ and the minima of Wolf's numbers appear in the 45-years' cycle-in the years: 1893, 1938, 1983.

Then, the west circulation undergoes the cyclic changes of 8,28 , 100 -years' periods and of $13,17,27$ days amplitudes - essential to $90 \%$ of confidence level ( $\left.F_{\text {comp }}>2.38\right)$.

Interesting are the cycles of meridional days number (the North and the South) of air circulation $T=3,8,16,24,55,>100$ years of amplitudes $b=10,9,14,13,20,16$ days. The cycles of $16,24,55$ and over 100 years are essential to $99 \%$ of level. It should be stressed that the strongest, the 55-years' cycle of meridional circulation of nearly 20-days' amplitu'de, is more or less equal to 56-years' cycle of the Sun's activity. The phase harmony of these cycles exists, too. The minima of meridional circulation of the 55-years' cycle appear in the years 1868, 1923, 1978 and in 2033, and the minima of Wolf's numbers in the 56-years' cycle appear in the years $1871,1927,1983$, and 2039. This indicates 
that the smaller or greater air flux from the North and the South to Central Europe every 55 years depends on the Sun's activity.

\section{THE PERIODICAL CHANGES OF AIR TEMPERATURE}

On the basis of the results of air temperature measurements in Warsaw in the years 1779-1979 (taken from the Institute of Meteoro$\log y$ and Water Management) the cycles $T_{r}$, their amplitudes $b$ and phases $c$ were established for each month (I, .., XII) and year (I-XII). The results of zero hypothesis verification $H\left(b_{r}=0\right)$, i.e. the comparison of counted values of Fisher's characterization $F_{\text {comp }}$ with critical numbers on $0.10,0.05,0.01$ of the significance level, at $n_{1}=2$ and $n_{2}-198$ degrees of freedom are very interesting.

The temperature cycles of 9-14-years' length: January-12, February-14, March-11, May-10, June-13, October-12, November-9 and December-10 years of amplitudes $b=0.77,0.88,0.67,0.41,0.21,0.38$, $0.39,0.68^{\circ} \mathrm{C}$ are essential to $90 \%$ of confidence level. It is known from another source that the range of $9-14$ years reduces the variability of the 11-years' cycle of the Sun's activity. The average annual air temperature in the years 1779-1979 shows the 13-years' cycle, essential to the same confidence level.

Similarly, the cycles of 20-24 years: January-23, March-20, April-24, May-21, June-21, August-22, September-20, November-22, and December-21 of amplitudes $b=0.76,0.58,0.66,0.43,0.37$, $0.35,0.47,0.48,0.71^{\circ} \mathrm{C}$, are essential to $90 \%$ of confidence level. Their lengths are similar to the 22-years' cycle of sunspots. There also exists a certain convergence of about 30,40,60-years' periods of temperature, the Sun's activity and atmospheric circulation. For example, Wolf's numbers show the 56-years' periodicity while an average annual air temperature shows the 60-years' periodicity.

Finally, the monthly value of air temperature undergoes fluctuations of long periods of $64-102$ and $149-250$ years. They are similar to multiperiodical cycles of the Sun's activity: 95 and 180 years. It is characteristic that, a long-term cycle of temperature of 64-102 years is stronger in summer than in winter while the 149-250-years' cycle behaves in the opposite direction. The 64-102-years' cycle, in summer months: June -90 , July -75 , and August -79 years of amplitudes $2 b=$ $=1.06,0.90,0.80^{\circ} \mathrm{C}$ is essential to at least $95 \%$ of confidence level. While, 149-250-years' cycle in a cool half-year: November-250, December-227, January-205, March-205, and April-232 years of amplitudes $2 \mathrm{~b}=1.94,2.24,2.74,1.48,3.30,1.18^{\circ} \mathrm{C}$ is essential to over $99 \%$ 


\begin{tabular}{|c|c|c|c|}
\hline$\frac{1}{\pi}$ & \multirow{5}{*}{ 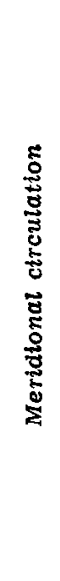 } & : & 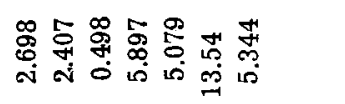 \\
\hline & & 㤎 & 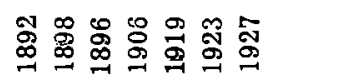 \\
\hline 8 & & 0 & 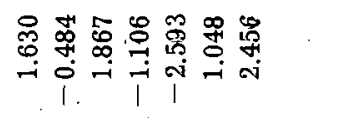 \\
\hline 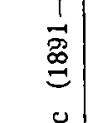 & & . & 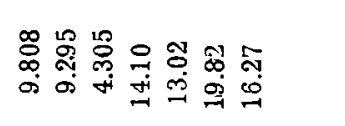 \\
\hline 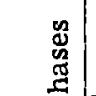 & & $\theta$ & 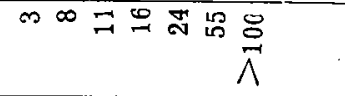 \\
\hline ב & \multirow{5}{*}{ 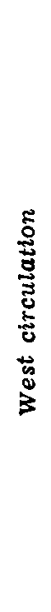 } & $\mid \begin{array}{r}\mid \\
0 \\
0 \\
0\end{array}$ & 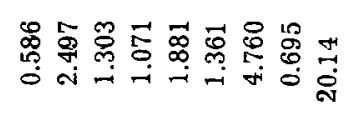 \\
\hline 总 & & 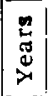 & 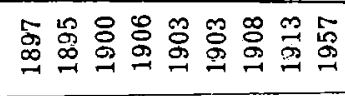 \\
\hline $\begin{array}{l}\overrightarrow{2} \\
\frac{a}{4} \\
\stackrel{4}{0}\end{array}$ & & 0 & 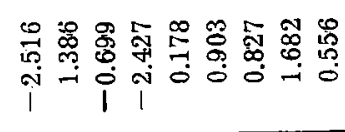 \\
\hline $\begin{array}{l}F-1 \\
\mathscr{a}\end{array}$ & & مـ & 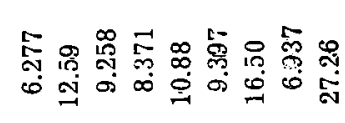 \\
\hline $\begin{array}{l}0 \\
己 \\
\Xi\end{array}$ & & $H$ & "⿻心 \\
\hline 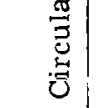 & \multirow{5}{*}{ 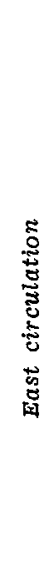 } & $\mid \begin{array}{c}2 \\
\vdots \\
0 \\
8 \\
2\end{array}$ & 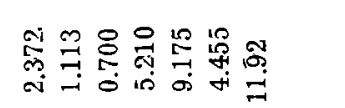 \\
\hline 总 & & 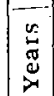 & 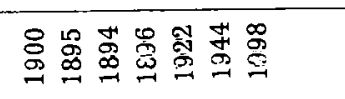 \\
\hline 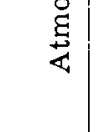 & & 0 & 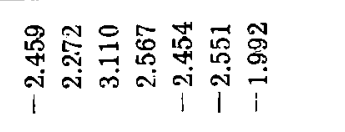 \\
\hline & & م. & 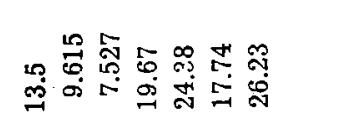 \\
\hline & & $E$ & 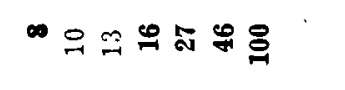 \\
\hline
\end{tabular}


of confidence level. Because the amplitude of that cycle is rather big (over $3^{\circ} \mathrm{C}$ ) it causes the multiperiodical temperature anomalies. The average annual values of air temperature in Warsaw in the years 1779-1979 reveal the cycles of 89 and 217 years, which only slightly differ from the cycles of Wolf's numbers of 95 and 180 years.

The minima of air temperature in the 89 -years' cycle occur in the following years: $1635,1724,1813,1902,1991,2080$ and the multiperiodical minima of the Sun's activity in the 95 -years' cycle occur in the years: $1622,1717,1812,1907,2002,2097$. Therefore, they are synchronous exactly to one 11-years' cycle. The annual minima of air temperature in the 217-years' cycle in the years $1610,1827,2044$ are well-known dates of climate „maunder minima”: 1619 and 1819 (Landsberg, 1980).

\section{THE AIR TEMPERATURE ANOMALIES IN THE 17TH-21ST CENTURIES}

The multiperiodical trend of air temperature was received by joining together the since curves (Boryczka, 1984)

$$
y=f(t)=a_{o}+a t+\sum_{r=1}^{R} b_{\mathrm{r}} \sin \left(\frac{2 \pi}{T_{\mathrm{r}}} t+c_{\mathrm{r}}\right)
$$

of relevant $T_{\mathrm{r}}$ periods, amplitudes $b_{\mathrm{r}}$ and phases $c_{\mathrm{r}}$.

The constant components of trend $\frac{\partial y}{\partial t}=a+\ldots$ show the growth of temperature in time limit which was caused, for instance, by the growth of dust and $\mathrm{CO}_{2}$ contents in the Earth's atmosphere. The linear part of trend $a_{0}+a t$ can also approximate the arc of sine curve of very long and unknown period.

The optimum trends $f(t)$ of monthly temperature value in January and July and of the average annual value in the years $1779-1979$ are illustrated by formulae (5), (6) and (7).

January $\left(F_{\text {comp }}=2.66\right)$

$$
\begin{aligned}
y= & -0,084+0,6726 \sin \left(\frac{2 \pi}{7} t+2.865\right)+0.793 \sin \left(\frac{2 \pi}{10} t+2.767\right)+ \\
& +0,7143 \sin \left(\frac{2 \pi}{13} t+0.7362\right)+0.5667 \sin \left(\frac{2 \pi}{15} t+0.5677\right)+ \\
& +0.6587 \sin \left(\frac{2 \pi}{23} t-2.001\right)+0.4041 \sin \left(\frac{2 \pi}{27} t-1.513\right)+ \\
& +0.5378 \sin \left(\frac{2 \pi}{44} t+0.8872\right)+0.5619 \sin \left(\frac{2 \pi}{64} t+0.3034\right)+
\end{aligned}
$$





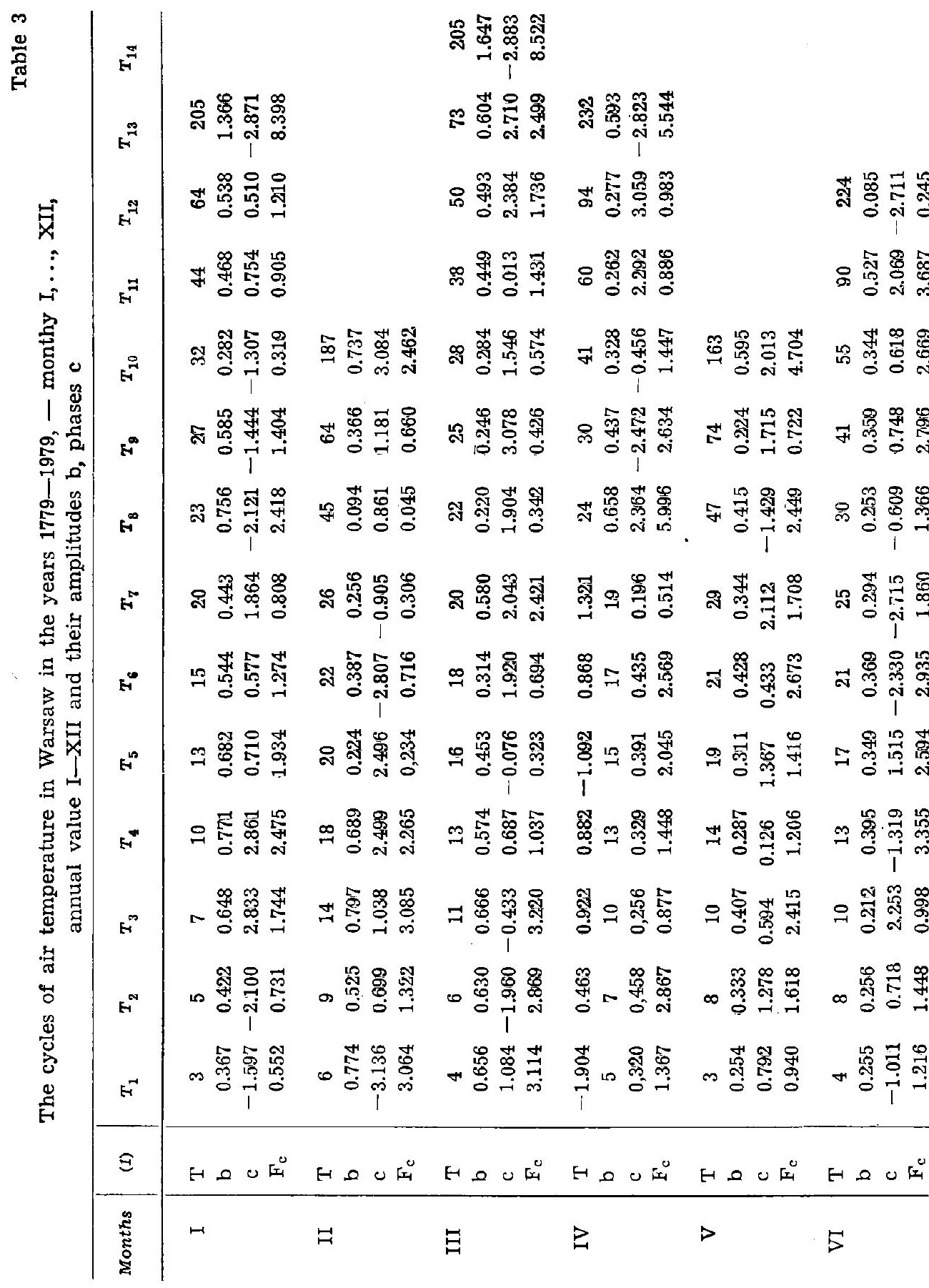




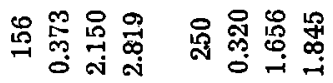

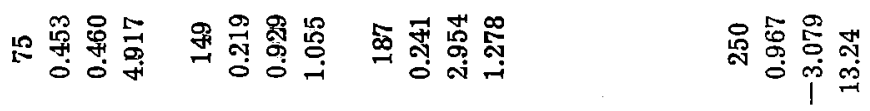

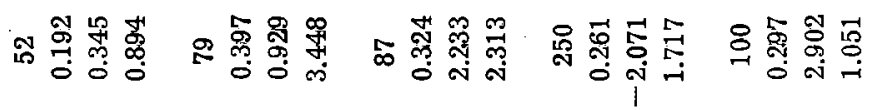

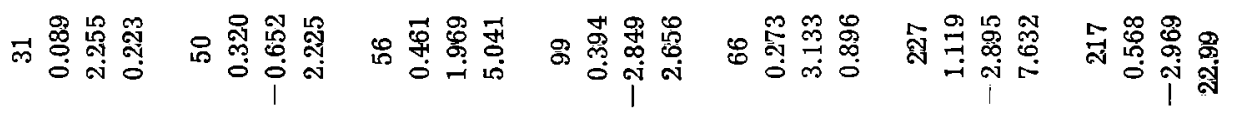

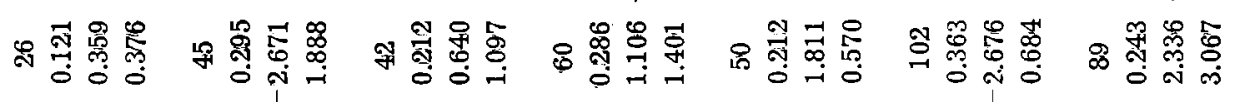

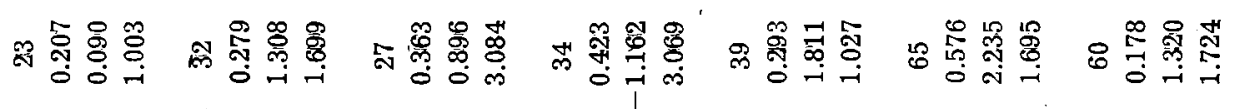

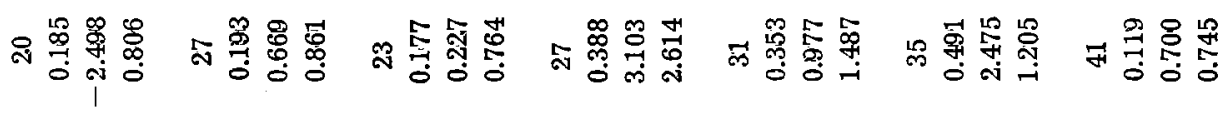

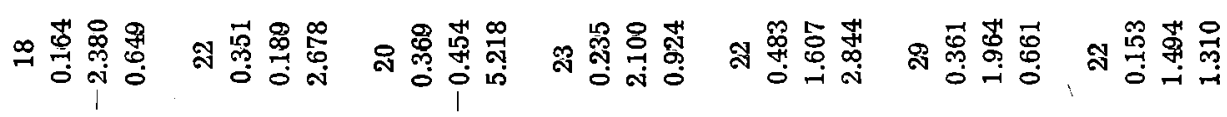

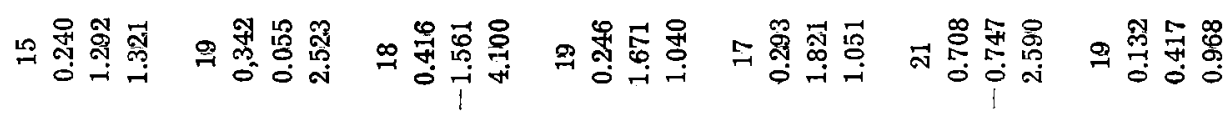

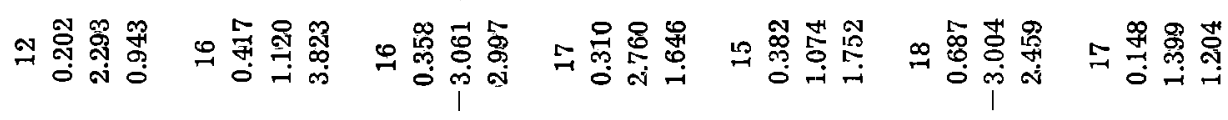

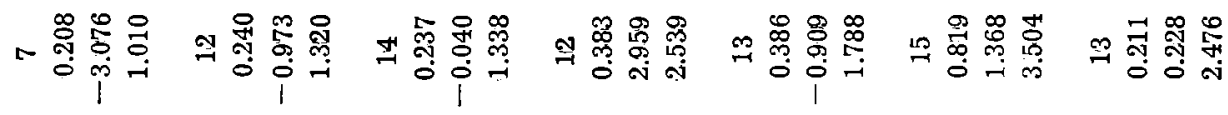

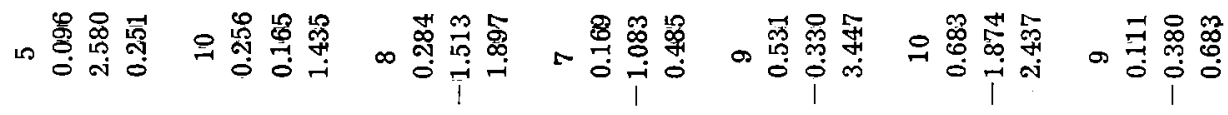

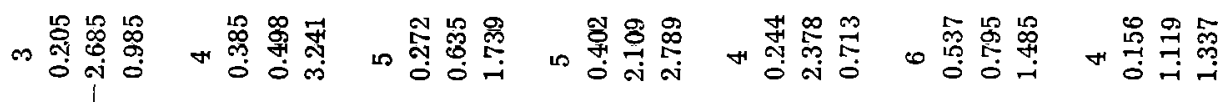

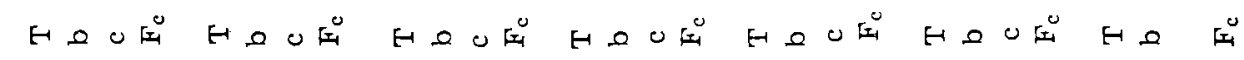

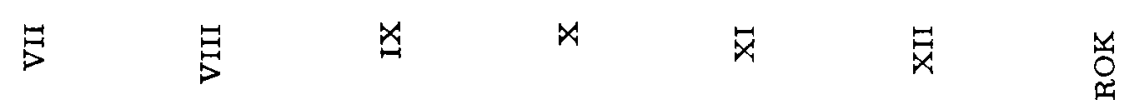





$$
+0.1402 \sin \left(\frac{2 \pi}{205} t-2.787\right)
$$

July $\left(F_{\text {comp }}=2.042\right)$

$$
\begin{aligned}
y= & 18.56+0.2191 \sin \left(\frac{2 \pi}{7} t-3.043\right)+0.2650 \sin \left(-\frac{2 \pi}{15} t+1.269\right)+ \\
& +0.2054 \sin \left(\frac{2 \pi}{23} t+0.0090\right)+0.4107 \sin \left(\frac{2 \pi}{75} t+0.3722\right)+ \\
& +0.2891 \sin \left(\frac{2 \pi}{156} t+2.288\right)
\end{aligned}
$$

$\operatorname{Year}\left(F_{\mathrm{comp}}=5.115\right)$

$$
\begin{aligned}
y= & 7.603-0.001504 t+0.1581 \sin \left(\frac{2 \pi}{4} t+1.132\right)+ \\
& +0.2029 \sin \left(\frac{2 \pi}{13} t+0.2304\right)+0.1507 \sin \left(\frac{2 \pi}{22} t+1.585\right)+ \\
& +0.1542 \sin \left(\frac{2 \pi}{60} t+1.769\right)+0.1700 \sin \left(\frac{2 \pi}{89} t+2.453\right)+ \\
& +0.6367 \sin \left(\frac{2 \pi}{217} t-2.916\right)
\end{aligned}
$$

They stimulate the most credible cycles of air temperature from among those listed in Table 3 . The zero hypothesis $H\left(b_{1}=\ldots=b_{R}=\right.$ $=0$ ) was verified by the comparison of calculated value of Fisher's characteristic ( $F_{\text {comp }}$ - of $n_{1}=2 R, n_{2}=N-2 R-1$ of degree of freedom) with critical numbers $F_{\text {critical on }} 0.05,0.01$ of significance level. Thu's, the hypothesis $H\left(b_{1}=\ldots=b_{\mathrm{R}}=0\right)$ is wrong on such levels of confidence as: January-99\% and July-95\%. The hypothesis $H(a=$ $=b_{1}=\ldots b_{\mathrm{R}}=0$ ) for the annual temperature value for $99 \%$ of confidence level is also untrue.

Extrapolating the value of aproximating functions (5), (6) and (7) within time interval $-279 \leqslant t<0$, the main temperature extrema of the 16th-18th centuries were reconstructed. Extrapolating the value of trends $f(t)$ within time $201<t \leqslant 521$, the forecast of air temperature anomaly in the 21st-23rd centuries, the so-called "sounding of future" was made. Parts of function's diagrams (5), (6) and (7) in the years $1779-2130$ are illustrated by the curves in Figures 1, 2 and 3. For the sake of comparison, time curves of monthly (January, July) and annual values of air temperature measured in Warsaw in the years 
1779 - 1979, were introduced. There is a great analogy between theoretical $f(t)$ and observational $y_{1}, \ldots, y_{\mathrm{N}}$ curves.

In January the lowest monthly value of temperature was recorded. in the following years:

date: $1803,1823,1850,1893,1940$

$y_{j}:-17.8,-14.1,-11.6,-13.1,-12.1^{\circ} \mathrm{C}$

Nevertheless the superposition of 9 sinusoidal cycles in that month. (formula 5) gives the main minima of temperature in the following years:

date: $1801,1823,1850,1892,1941$

$\mathrm{y}_{\min }:-8.6,-7.0,-7.6,-7.1,-7.0^{\circ} \mathrm{C}$

The absolute minimum of theoretical curve $y_{\min }=8.6^{\circ} \mathrm{C}$ ) (1801) differs only about one year from the date when the absolute temperature minimum $-17.8^{\circ} \mathrm{C}(1803)$ was measured. It also differs only about one 11-years' cycle from the minimum of the absolute Sun's activity. The reconstructed main minima of the 16th-18th centuries which appeared in $1592\left(\mathrm{y}_{\min }=-8.3^{\circ} \mathrm{C}\right)$ and in $1621\left(\mathrm{y}_{\min }=-8.1^{\circ} \mathrm{C}\right)$ are very close to the year 1619 - the date of temperature "maunder minimum". Similar minima of temperature, as they were on the turn of the 15th /16th and 17th/18th centuries could be expected in the years: $2011\left(y_{\min }=\right.$ $\left.=-7.9^{\circ} \mathrm{C}\right), 2032\left(y_{\min }=-7.8^{\circ} \mathrm{C}\right)$ and in $2243\left(y_{\min }=-7.9^{\circ} \mathrm{C}\right)$.

In July, there exists quite a big compatibility in time of computed (according to formula 6) and measured main temperature minima. The dates of the coolest Julies are listed below:

date: $1800,1815,1832,1844,1898,1979$

$\mathrm{y}_{\mathrm{j}}: 15.9,15.7,14.1,15.3,15.6,15.1^{\circ} \mathrm{C}$

Whereas the curve's minima (6) appear in the years:

date: $1801,1815,1943,1907,1981$

$y_{\text {min }}: 18.4,17.7,17.6,17.8,17.3^{\circ} \mathrm{C}$

Similar minima of temperature appeared in $1512\left(y_{\min }=17.6^{\circ} \mathrm{C}\right)$, $1683\left(y_{\min }=17.8^{\circ} \mathrm{C}\right)$, and they could be expected near the dates: 2054 $\left(y_{\min }=18.0^{\circ} \mathrm{C}\right), 2117\left(y_{\min }=17.7^{\circ} \mathrm{C}\right), 2145\left(y_{\min }=17.6^{\circ} \mathrm{C}\right)$ and in 2208. $\left(y_{\min }=17.7^{\circ} \mathrm{C}\right)$.

Of special cognitive importance in climatology are the implications resulting from formula (17) which introduces the multiperiodical changes of average annual value of air temperature in Warsaw over the past centuries. The function, approximating empirical data from the years $1779-1979$ has ,the deep" minima in the years:

date: $1633,1812,2049,2257$

$y_{\min }: \quad 6,6, \quad 6.2, \quad 6.1, \quad 5.8^{\circ} \mathrm{C}$ 



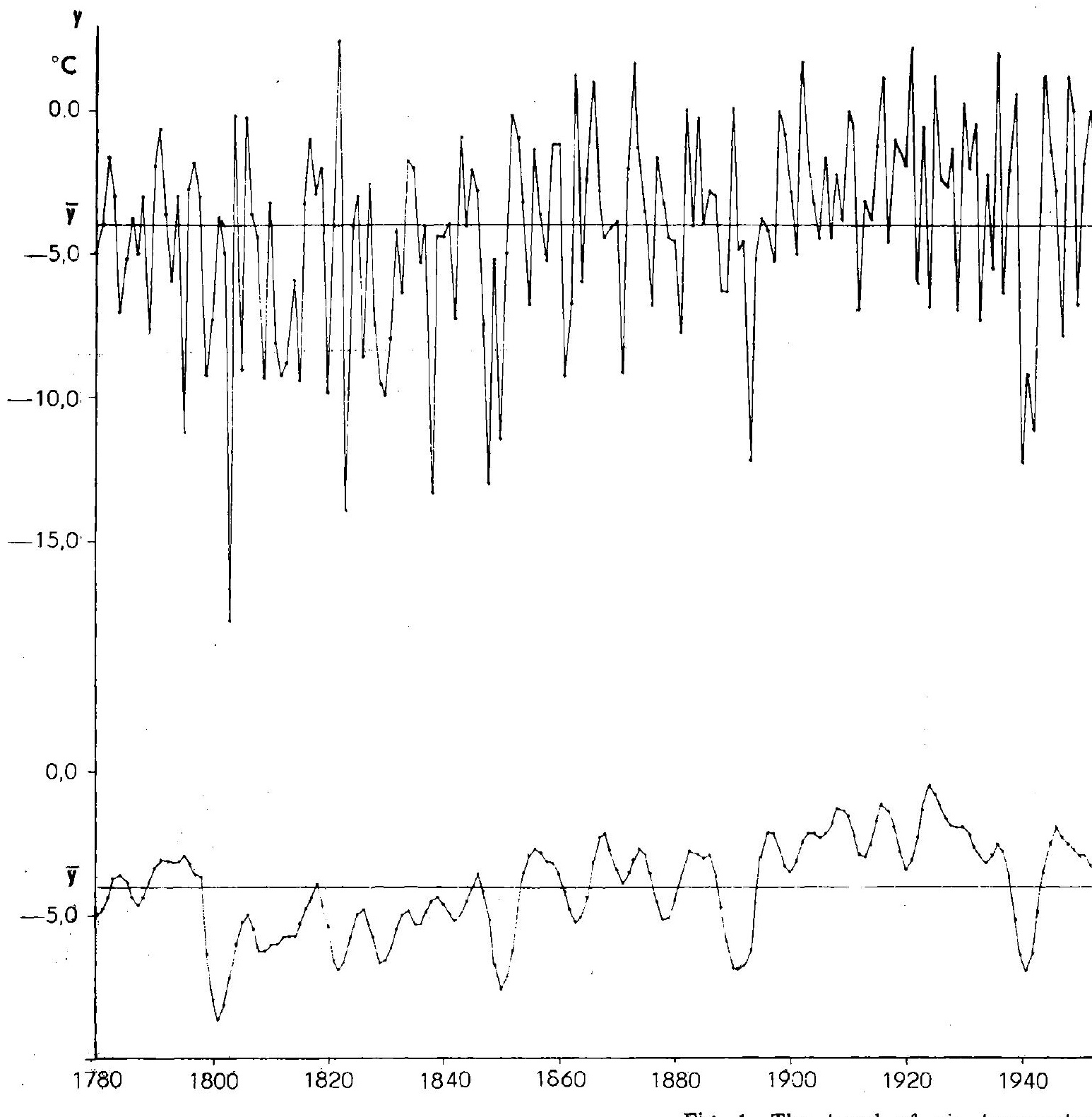

Figg. 1. The trend of air temperatur (January)

a) observation data in the years 1779-1979

b) the diagram of aproximating function (5) 


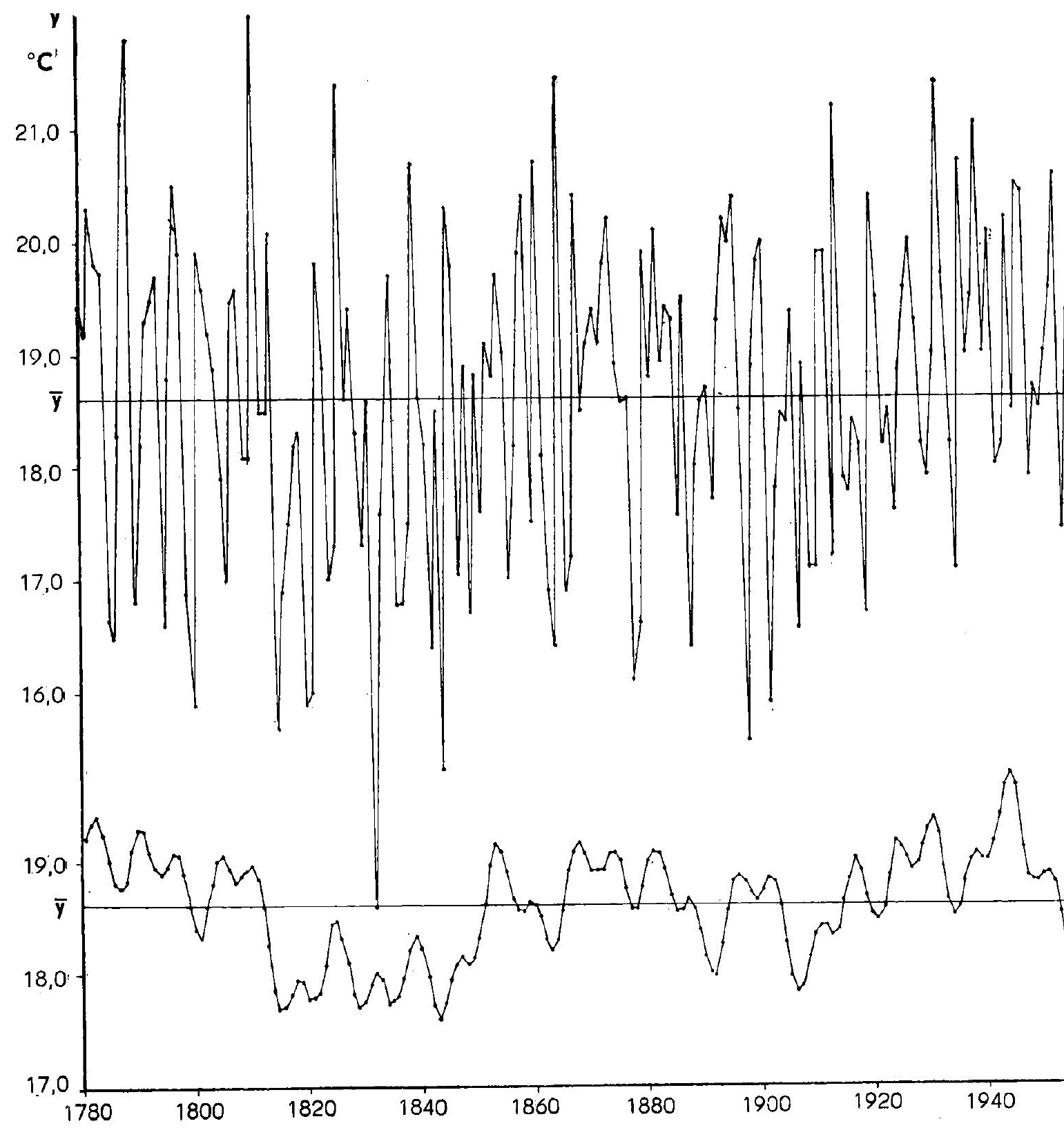

Fig. 2. The trend of air temperatur (July)

a) observation data in the years $1779-1979$

b) the diagram of aproximating function (6) 


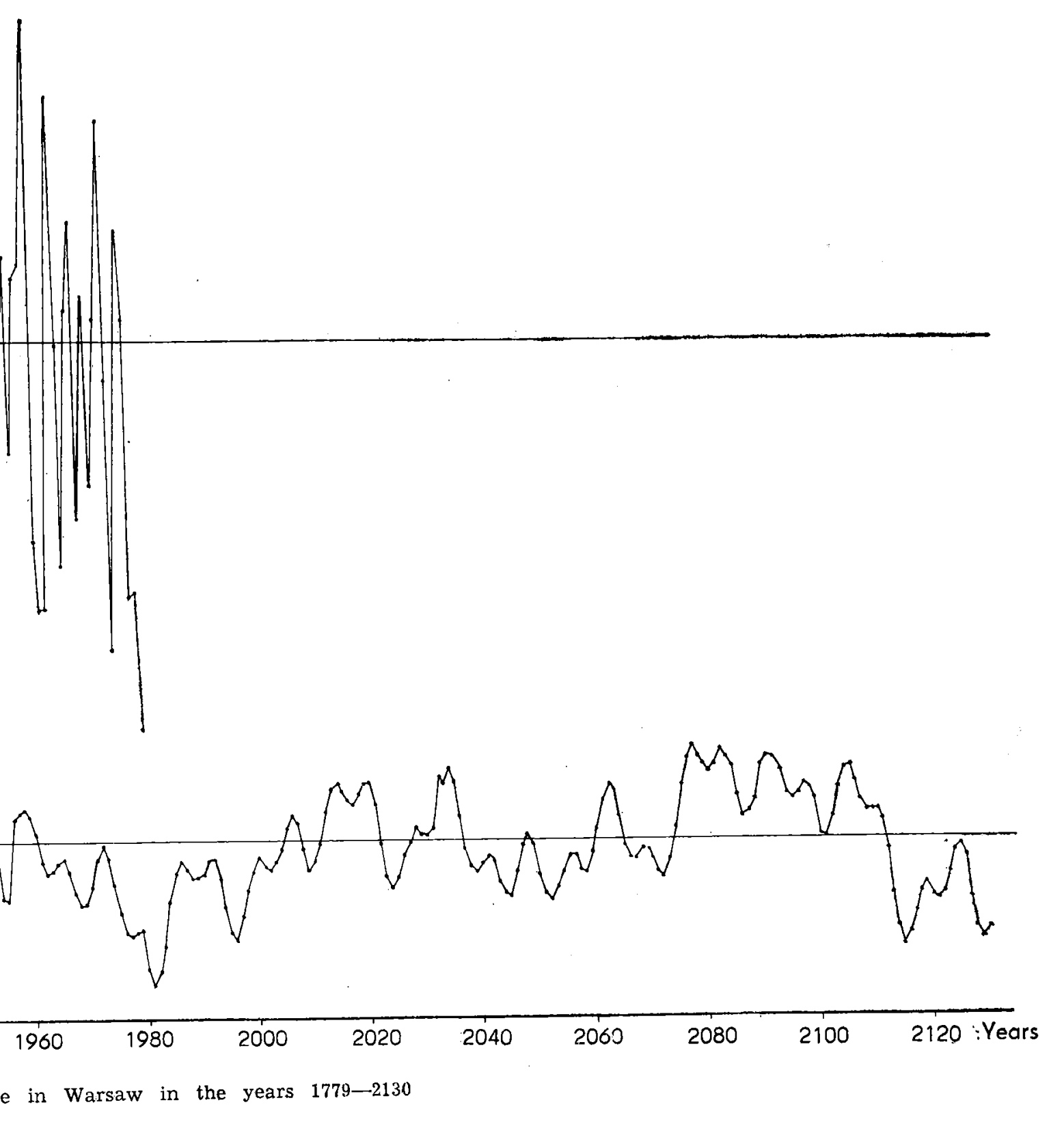




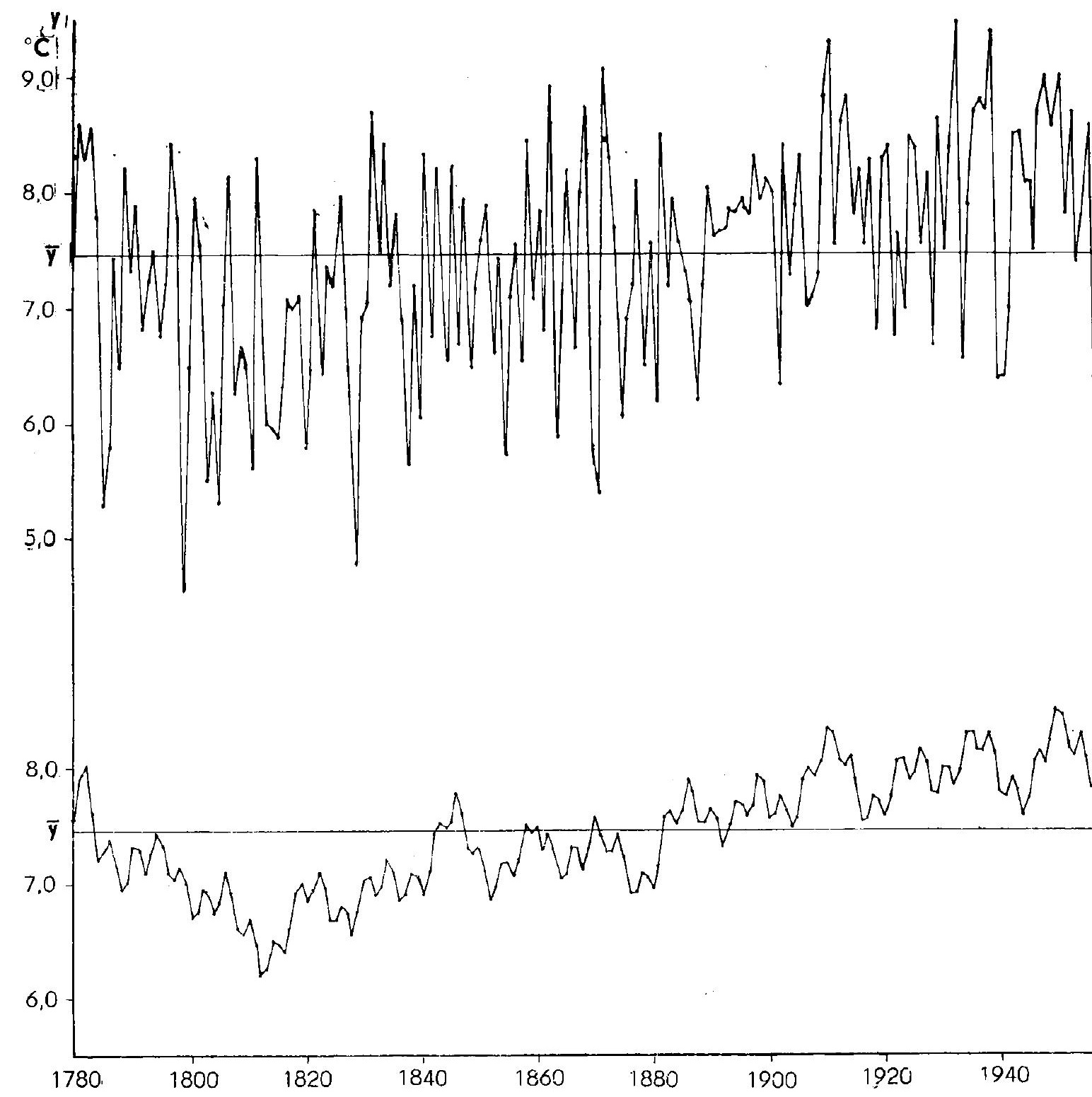

Fig. 3. The trend of air temperatur (Year)

a) observation data in the years 1779-1979

b) the diagram of aproximating function (7) 


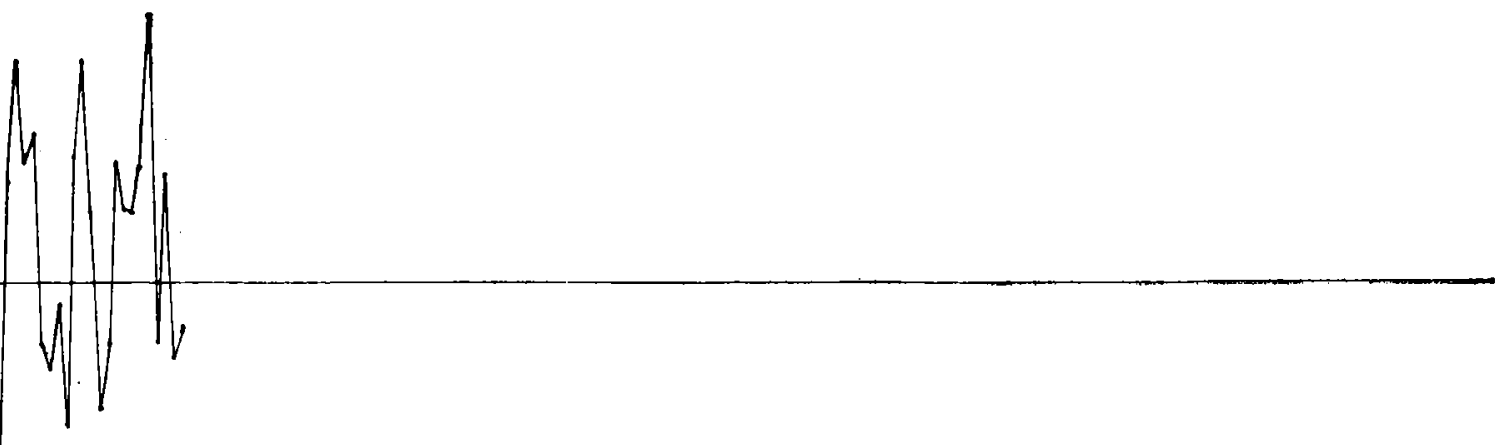

b

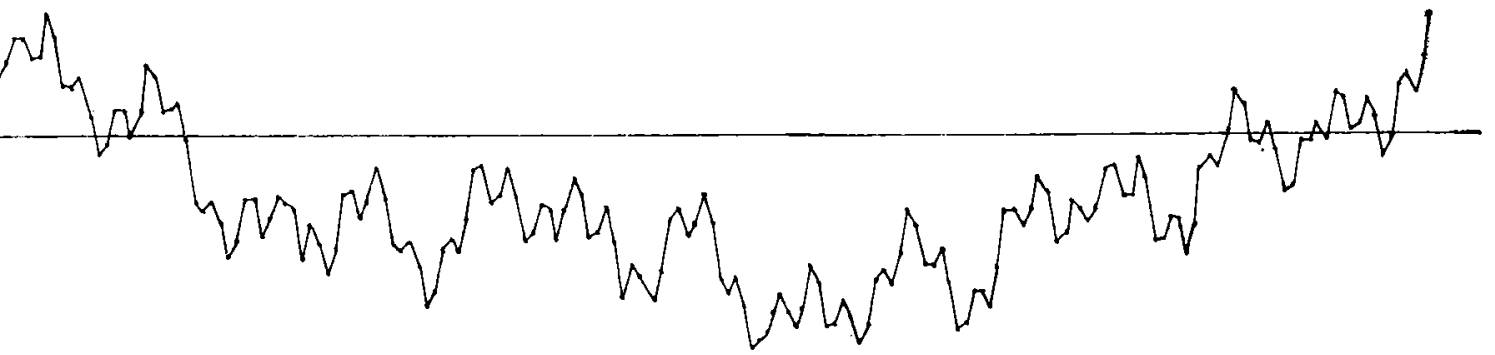

$\begin{array}{llllllll}1960 & 1980 & 2000 & 2020 & 2040 & 2060 & 2080 & 2 !\end{array} \quad 2120$ Years

in Warsaw in the years $1779-2130$ 

Two first dates specify the time of existence of known "maunder minima" of air temperature on the Earth in the years: 1619 and 1819 (Landsberg, 1980). The absolute minimum of annual average temperature in Warsaw within the observation interval (1812) is the lower limit of the weakest 11-years' cycle of the Sun's activity in the years 1811-1823. Multiperiodical maxima of annual temperature occur in the years:

date: $1495,1715,1950,2131$

$y_{\max }: \quad 9.3, \quad 8.7, \quad 8.5, \quad 8.2^{\circ} \mathrm{C}$

The absolute maximum of annual average temperature in the years $1779-1979$ (1950) is slightly ahead of the date of the strongest 11-years' cycle of sunspots in the years 1955-1964 and is ahead of the absolute maximum date of Wolf's numbers (1957).

The probability of crossing the trend's line $f(t)$ (in plus or in minus) can be defined on the basis of the size of remainder $\varepsilon_{j}=y_{j}-f\left(t_{j}\right)$ (Table 4). The remainder deviations $\varepsilon=\sqrt{\varepsilon^{2}}$ are: January $\varepsilon=3.100$;

Table 4

The Distribution of Remainder Size $\varepsilon_{\mathrm{j}}=y_{\mathrm{j}}-f(t j)$

in Months: January, July and within a Year

\begin{tabular}{c|c|c|c}
\hline$\varepsilon_{j} / \varepsilon$ & January & July & Year \\
\hline$<-3.0$ & 1 & 0 & 0 \\
$-3.0--2.0$ & 6 & 3 & 6 \\
$-2.0--1.0$ & 26 & 33 & 31 \\
$-1.0-0.0$ & 56 & 59 & 54 \\
$0.0-0.1$ & 86 & 73 & 84 \\
$0.0-2.0$ & 25 & 29 & 24 \\
$2.0-3.0$ & 1 & 4 & 2 \\
$>3.0$ & 0 & 0 & 0 \\
\hline
\end{tabular}

July $\varepsilon=1.424$; a year $\varepsilon=0.829^{\circ} \mathrm{C}$. For example, the probability of annual temperature occurrence in an interval $f(t) \pm \varepsilon$ is $68,7 \%$ and the occurrence of higher temperature than $f(t)+2 \varepsilon$ is less than $1 \%$.

In conclusion, we can note that at present "we are" in the declining part of the curve of average annual temperature values, below the "standard" i.e. the average 201 years equal to $7.46^{\circ} \mathrm{C}$, It refers both to the whole year and to extreme months:

January - below the average $\vec{y}=-4.02^{\circ} \mathrm{C}$ and $\mathrm{July}-\vec{y}=18.58^{\circ} \mathrm{C}$. In the last two decades of the 20th century the declining tendency of monthly average temperature in January and the growth of average temperature in July should be observed. Naturally, temperature of those months will undergo short-term fluctuation of great amplitudes. 
Formula (7) also implicates another important conclusion. In Warsaw, in the years $1779-1979$ there existed a constant decreasing tendency of annual air temperature values $a=-0.15^{\circ} \mathrm{C} / 100$ years. It is probably the total effect of growth of dust and $\mathrm{CO}_{2}$ concentration in the Earth's atmosphere in recent years.

Multiperiodical changes of climatological elements in Poland, with special reference to Warsaw, have been the fundamental research problems of the Chair of Climatology of the Faculty of Geography and Regional Studies of Warsaw University (Kaczonowska, 1962; Okołowicz, 1964; Stopa-Boryczka, 1973; Kossowska 1973; Kopacz-Lembowicz, 1978).

\section{BIBLIOGRAPHY}

B oryczka J., "Model deterministyczno-stachastyczny wielookresowych zmian klimatu" (Deterministic and Stochastic Model of Multiperiodical Climate Changes), Rozprawy Uniwersytetu Warszawskiego, No. 234, Warszawa 1984.

Kaczorowska Z., "Opady w Polsce w przekroju wieloletnim" (Precipitation in Poland in Long-period Averages), Prace Geograficzne IG PAN, No. 33, Warszawa 1962.

Kopacz-Lembowicz M., "Bioklimat Uzdrowisk o profilu kardiologicznym" (The Bioclimate of Health Resorts in the Domain of Cardiology), Prace i Studia IGUW - Klimatologia, No. 10, Warszawa 1978.

Kossowska-Cezak U., "Warunki termiczne Warszawy" (Thermic Conditions in Warsaw), Prace i Studia IGUW - Klimatologia, No. 9, Warszawa 1977.

Okołowicz W., "Zachmurzenie Polski" (Cloudiness in Poland), Prace Geograficzne IG PAN, No. 34, Warszawa 1962.

Reznikiov A.P., Priedskazaniye yestiestviennykh prociesov obuchayushchieysia sistiemoi, Izdatielstwo „Nauka”, Novosibirsk, 1982.

Stachy J., "Wieloletnia zmienność odpływu rzek polskich w bieżącym stuleciu" (The Perennial Changeability of Outflow of Polish Rivers in the Current Century), Prace PIHM, No. 95, Warszawa 1970.

Stopa-Boryczka M., "Cechy termiczne klimatu Polski" (The Thermic Features of Polish Climate), Rozprawy Uniwersytetu Warszawskiego, No. 72, Warszawa 1973. 